\title{
Research on the Structure and Techniques of Prehistoric Footwear Unearthed from Xinjiang*
}

\author{
Xiaoyu Xin \\ College of Textile and Clothing \\ Xinjiang University \\ Urumqi, China 830046
}

\begin{abstract}
Based on the prehistoric archaeological footwear excavated from Xinjiang, the essay analyze the characteristics of the structures and techniques of those footwear according to early stage, middle stage and late stage of this period, and find out that it had been developing constantly during almost 2000 years. And the style had been more and more abundant while the structures more and more reasonable. With the continuous improvement of the footwear techniques, the match of the materials had been increasingly diverse, showing the primitive exploring of the ancient residents of Xinjiang in footwear making.
\end{abstract}

Keywords-Xinjiang; prehistoric; footwear; structures; techniques

\section{INTRODUCTION}

As important articles for foot protection, footwear plays a vital role in the life of ancient residents of Xinjiang. Due to the geological environment of desert, oasis and grassland co-existing, ancient residents of Xinjiang attach extreme importance to the function of footwear, like heat retention and comfort. Archaeological evidence proves that, as early as in the Bronze Age, BC 2000, residents of ancient times in Xinjiang starts wearing footwear for foot protection. Most of the prehistoric[1] footwear unearthed from Xinjiang is the leather boot which is mainly made of felt and animal fur and falls into four kinds due to the length of boot leg: short boot, medium-length boot, long boot and panty leather boot. Its shape and structure constantly get improved in its almost 2000 years' development and evolve into various forms. For the convenience of research, the paper divides the prehistoric footwear unearthed from Xinjiang into three phases: early, mid-term and later phases due to its archaeological date, conducts an analysis on features of structures and techniques of footwear in each phase and conducts a preliminary discussion on the basic law of its development and change.

\section{EARLY PHASE (BC 2000 TO BC 1300)}

According to archaeological division of history, the early phase of prehistoric footwear unearthed from Xinjiang is between BC 2000 and BC 1300. Most footwear is the

*It is a project supported by the National Social Science Fund (Art) of China,2015.(Grant No.15CG160). Project Name: The Early Costumes of Xinjiang before Han Dynasty. short leather boot, which mainly unearthed from the area around Lop Nor with similar shape, structure and style: mostly flat sole, round toe, opening in front of boot leg and fixation at the ankle with thin and narrow strap or woolen yarn with rough and unadorned earthy style and typical primitive features. In Chinese ancient literature, this kind of leather $\mathrm{Hu}$ boot with thin bottom, boot leg and drawstring is called “Suo Ze", “Su Zhu” or “鞋殬” [2], referring to boots with the bundle of cord or leather strap. Its birth time is earlier than Shang and Zhou Dynasties as a description of footwear of minorities in the Western Regions. In Shi You's Fast Learning of Western Han Dynasty, there is "Barbarians wearing felt, fur coats and weather boots"[3], vividly describing the image of ancient residents in Western Regions wearing felt, fur clothes and puttee leather boots. In Eastern Han Dynasty, Liu Xi's Notes to Nominations • Notes to Clothes records "Su Zhu refers to leather boots lacking the forepart of boot leg, a name used by $\mathrm{Hu}$ people. $\mathrm{Su} \mathrm{Zhu}$ is a kind of footwear and people can walk forward by wearing it"[4]. It describes the shape and structure features of Su Zhu as leather boots used by the Western $\mathrm{Hu}$ people, which lack the forepart of boot leg. The leather boots of early phase before Han Dynasty unearthed from Xinjiang completely conform to the above shape and structure of "Su Zhu", listed as the earliest Su Zhu unearthed.

\section{A. Structure}

Leather boots of early phase can fall into two types in terms of structure: three-piece and two-piece. The threepiece boots refer to boots consisting of three pieces of material: sole, vamp and boot leg. There is evident joint trace along middle left and right sides of boots' surface. It is the most common seen type of leather boots of early phase. The two-piece boots refer to boots consisting of two pieces of leather material: sole and the joint piece of leather material of boot leg and vamp.

\section{1) Three-pieces structure}

Leather boots with three-piece structure are mainly unearthed from Peacock River Gumugou cemetery, Xiaohe cemetery in Lop Nor and Keriyan Northern cemetery. Its main material is animal skin with fur on the other side. It is common to see inward fur on vamp and boot leg and outward fur on soles. Boot leg is 9 to $28 \mathrm{~cm}$ tall, vamp is 8 to $14 \mathrm{~cm}$ wide and the sole is 13 to $29 \mathrm{~cm}$ long. 
Three-piece leather boot unearthed from different cemeteries has certain regional features. For example, boots unearthed from Gumugou cemetery have their boot leg stitched on the vamp and leather sole from the behind to the front. On the middle front part of the vamp, lies a small opening of about 3 or $4 \mathrm{~cm}$ long for the convenience of putting on and taking off. There are pinholes on the left and right sides of boot leg's front opening for the convenience of fixation with a piece of woolen yarn or leather strap going through the pinhole. "Fig. 1"
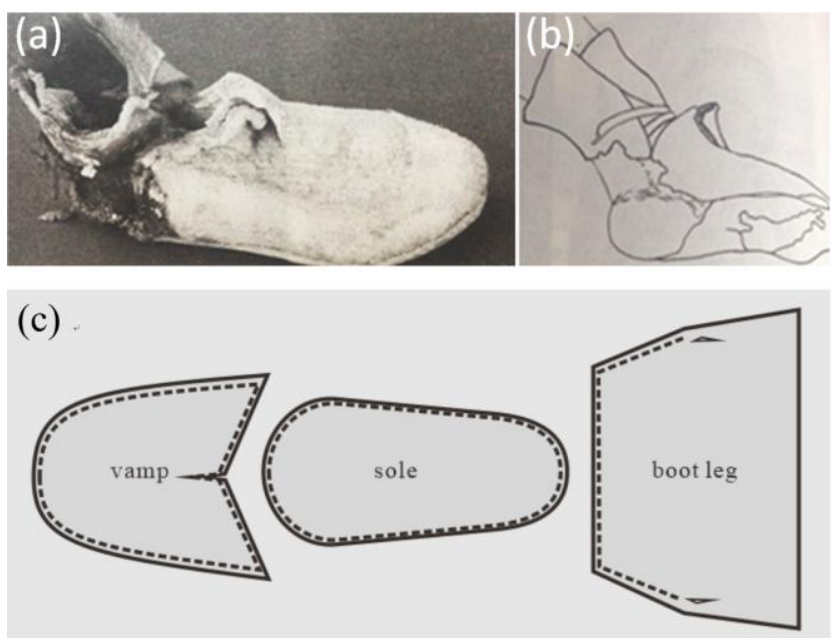

(a) Photo (b) Sketch (c) Pattern of the structure

Fig. 1. Leather boots unearthed from Gumugou cemetery.

Leather boots unearthed from Xiaohe cemetery and Keriyan Northern cemetery are similar in shape and structure without openings in the middle front part of vamp and with leather boot leg directly stitched in the margin of vamp and with a slightly higher bootleg compared with leather boots unearthed from Gumugou etc. Take a pair of leather boots unearthed from Xiaohe cemetery as an example, their height is about $22.5 \mathrm{~cm}$ with a $29 \mathrm{~cm}$ long sole, a $13.5 \mathrm{~cm}$ front width and a $9 \mathrm{~cm}$ back width. The boots consist of three pieces of leather: sole, vamp and bootleg with inward fur on bootleg and outward fur on the sole [5]. There is a protruding arris on the left and right sides of boot sole's middle edge for the convenience of piecing the vamp and bootleg. Its bootleg is similar to that of Gumugou leather boots and has pinholes on both sides, through which woolen yarn goes and bypasses the ankle for fixation. In terms of their characteristic surface decorations, there are red vertical lines right in the middle of the vamp and several pinholes near the seam crossing at the top, into which feather and red woolen yarn are inserted in a matched way, boasting unique decorative features. "Fig. 2"
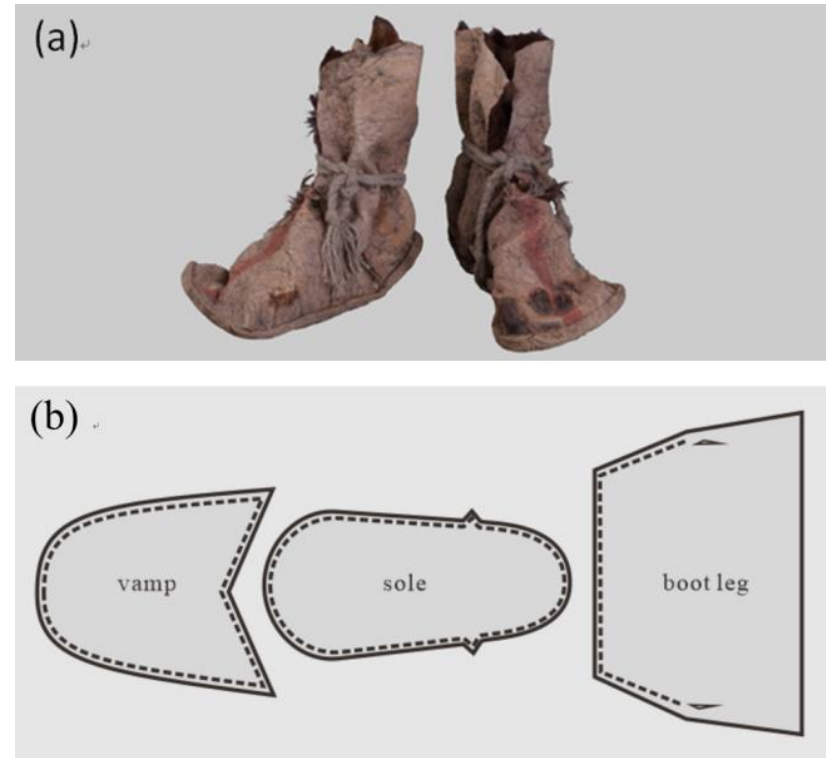

(a) Photo (b) Pattern of the structure

Fig. 2. Leather boots unearthed from Xiaohe cemetery.

\section{2) Two-pieces structure}

Leather boots with two-pieces structure are mainly unearthed from Grave 36, Qum-darya and Bronze Age cemetery near LE and their time is slightly later than leather boots unearthed from Gumugou. The two-piece leather boots consist of two pieces of leather: sole and the joint piece of bootleg and vamp. Stitch only exists on one side of the surface.

Take leather boots unearthed from Grave 36, Qum-darya as an example, their height is $26.5 \mathrm{~cm}$ and width is $10.5 \mathrm{~cm}$ with a bootleg height of $18 \mathrm{~cm}$. The sole is in irregular oval with wide front and narrow back. Small notches on both edge sides of the part between the heelpiece and arch of the foot should be the alignment mark to form a seam. The vamp and bootleg are in a whole piece of leather. There is a small triangle skin as auxiliary structure near the front and middle seam. An opening exists along the seam crossing of vamp to form the joint three-dimensional contouring of bootleg and vamp, stitching the sole to the upper. The bootleg has an opening in front with one hole on each side, through which leather strap goes for fixation. The upper edge of bootleg is cut into zigzag with three red woolen yarn and several broken feathers[6] on toe cap, boasting exquisite structure design. "Fig. 3" 

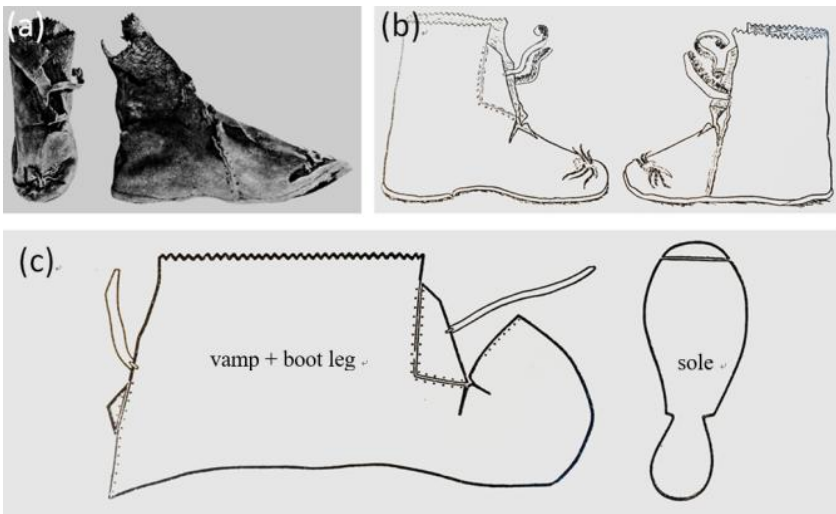

(a) Photo (b) Sketch (c) Pattern of the structure

Fig. 3. Leather boots unearthed from Grave 36, Qum-darya [7].

\section{B. Sewing Craft}

Luo Chongqi puts forward three achievements in craft history of ancient "leather shoes": side and bottom breaking, reasonable design of vamp and stitching the sole to the upper from the inside[8]. Prehistoric early leather boots unearthed from Xinjiang have experienced "side and bottom breaking" and "turned-stitching techniques", reflecting a high technical level.

Archaeological evidence shows that three-piece and two-piece leather boots from prehistoric Xinjiang have realized side and bottom breaking and use a thin animal ligament rope to stitch leather material into boots. In addition, the common seen "embossment" on both sides of three-piece leather boots' sole and "notch" on the sole of two-piece leather boots should be used as alignment mark to determine the suture location of bootleg, vamp and sole. The bulging part is also in favor of stitching of leather boots in later process.

As to stitching the sole to the upper of footwear, there are generally two ways: "direct-stitching" and "turnedstitching". The former refers to connecting two pieces of leather material directly with seam allowance outside whereas the latter leaves seam allowance inside the footwear with a bright, clean and smooth external seam. Seen from archaeological material objects, in early Bronze Age, Xinjiang residents have mastered turned-stitching techniques and even the "smooth on both sides" stitching techniques, reflecting the high technical level. "Fig. 4"
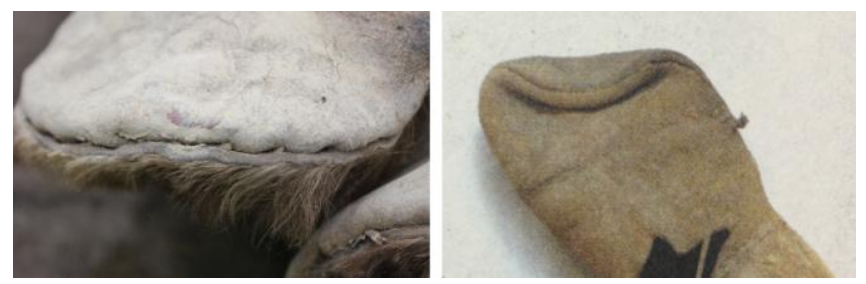

(a) Leather boots from Xiaohe cemetery

(b) Leather boots from a place near Grave LE

Fig. 4. Turned-stitching techniques during early period

\section{MID-TERM PhASE(BC 1300-BC 800)}

Material objects of prehistoric footwear of mid-term phase unearthed from Xinjiang mainly come from Wupu, Askchar, Yanbulake cemeteries in Hami basin, and Yanghai early cemetery, Shanshan between BC 1300 and BC 800 . Leather boots unearthed in this period are mainly ankle boots with few thigh boots with a height of about $30 \mathrm{~cm}$, boasting more diversified shape and structure. Footwear with four-piece structure (sole, vamp, upper and bootleg) begins to emerge. With development of bronze civilization, copper sheet begins to appear on vamp as decoration, signifying progress of production technology in this period.

\section{A. Structure}

Structure of leather boots in mid-term phase is more stylized compared with that of early boots. The structural design of separated vamp and upper is more reasonable. Apart from the three-piece structure of early phase, the fourpiece structure of separated sole, vamp, upper and bootleg appears, reflecting boots making technical progress. Apart from the round toe modeling similar to that of early phase, pointed toe appears with lighter and more convenient shape and structure which fit the feet more, reflecting early exploration of ancient Xinjiang residents on modeling and structure of footwear.

\section{1) Three-pieces structure}

Leather boots with three-piece structure in this period are similar to those of early phase: The boots consist of three pieces: sole, vamp and bootleg through stitching. Pointed toe modeling begins to appear on the basis of leather boots with round toe. For example, the pair of pointed leather boots unearthed from Grave M157, Yanghai No. 1 cemetery, Shanshan, has a height of $26 \mathrm{~cm}$ with a 26.5 $\mathrm{cm}$ long sole. The pointed toe stretches forward in a straight way. Sole, vamp and upper are made from a piece of cattlehide respectively whereas the bootleg is made from sheepskin with copper decorations on vamp [9]. In addition, some pointed boottoes upwarp and even are folded, boasting unique modeling. Take a pair of folded leather boots unearthed from Wupu cemetery, Hami as an example; they have a pass length of 22 to $23.5 \mathrm{~cm}$, a height of 20 to $21 \mathrm{~cm}$ and a sole width of 9.5 to $11 \mathrm{~cm}$. They consist of three leather pieces: vamp, sole and bootleg through stitching with pointed and folded boot head decorated with nail brass buckle ornament. There are also brass buckle decorations on both sides of heels and bootleg[10]. "Fig. 5" 

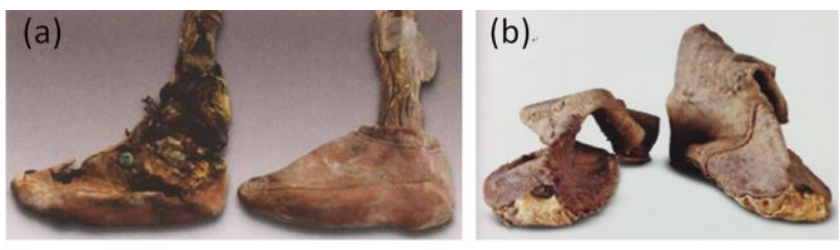

(c)

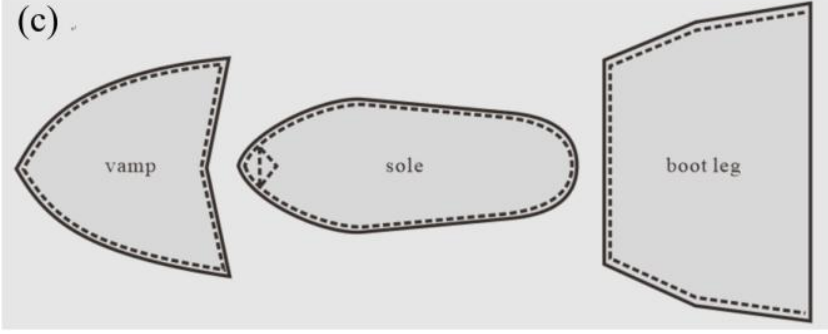

(a) Photo of pointed leather boots from Yanghai cemetery

(b) photo of folded leather boots from Wupu, Hami

(c) pattern of the structure of pointed boots

Fig. 5. Pointed leather boots with three-pieces structure.

\section{2) Four-pieces structure}

Leather boots with four-piece structure and separated vamp and upper appear in this period, showing further improvement of boots making techniques, more reasonable structure and more stylized making process. For example, the flat round-toe leather boots unearthed from Wupu cemetery, Hami adopt the four-piece structure of separated sole, vamp, upper and bootleg. The sole consists of three layers of cattlehide with a thickness of $0.5 \mathrm{~cm}$ and a length of about $26 \mathrm{~cm}$. The two pieces of cattlehide material of upper and vamp are sutured whereas the $18 \mathrm{~cm}$ tall bootleg is stitched to the upper. "Fig. 6"
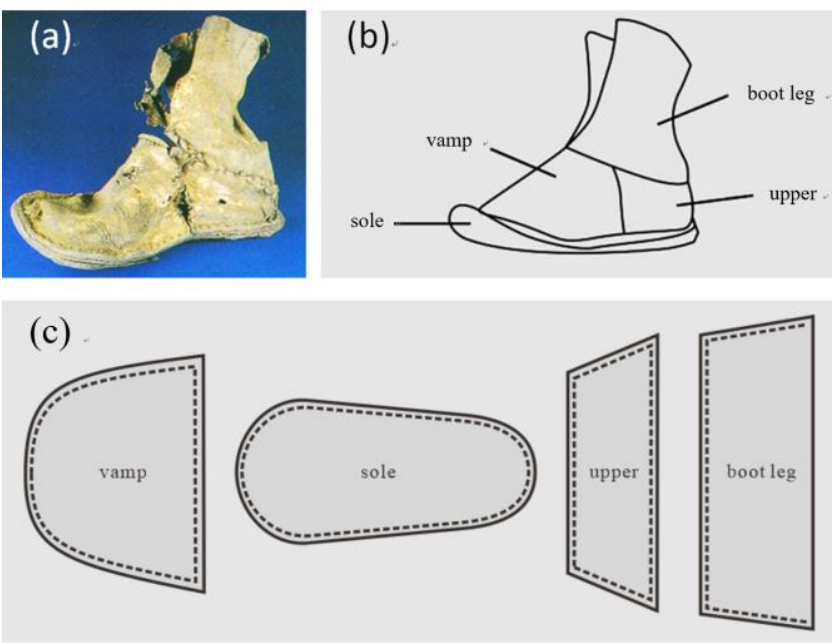

(a) Photo (b) Sketch (c) Pattern of the structure

Fig. 6. Round-toe leather boots with four-pieces structure unearthed from Wupu, Hami.

\section{B. Sewing Craft}

Seen from manufacturing craft, tanning and sewing techniques of leather boots unearthed in this period get improved. Most of the leather boots are made of tanned leather with great improvement in tanning techniques. In addition, leather material is selected according to structure and location. For example, bootleg adopts soft sheepskin as the material whereas the sole, upper and vamp use relatively thick cattlehide [11]. Evident progress can be seen in sewing craft. The sole and vamp adopt the turned-stitching techniques making both sides smooth. Leather boots boast fine craftsmanship and begin to cut leather into very thin hide rope for sewing, the integrated technical level boasting evident progress compared with early phase.

\section{LATER PHASE(BC 800 TO BC 200)}

Prehistoric leather boots of later phase are mainly unearthed from Zhagunluke II Culture Cemetery, Qiemo, Subeixi cemetery, Shanshan, Yanghai cemetery of the early Iron Age and Three Bridges I Culture Cemetery, Shanshan in Xinjiang from BC 800 to BC 200 or so. In this period, ancient residents of Xinjiang use footwear with more diversified shape and further improved structure. People gradually form the habit to use foot-binding cloth or wear felt socks inside footwear. Selecting and combining of footwear material are more diversified, mostly using tough cattlehide to make the sole and soft sheepskin, deerskin or felt to make bootleg. Different materials are used in a reasonable way. Manufacturing craft of footwear gradually becomes mature with exquisite and beautiful sewing, showing new features of the times.

\section{A. Structure}

Structure of footwear in later phase is the most diversified during the 2000 years before Christ. Processing craft of footwear gets greatly improved, with appearance of leather boots with three-piece (structure upper and vamp-inone and separately cut sole) and pleated-sewing footwear. On the other hand, corresponding to the prevailing of pants and clothes length reduced, the height of bootleg gets enhanced gradually with the initial appearance of thigh-high boots and even panty boots.

\section{1) Three-pieces structure with upper and vamp-in-one}

Different from the three-piece structure of early phase with vamp and bootleg stitched to the sole, the three-piece structure with upper and vamp-in-one gradually becomes popular in this period. Take ankle boots unearthed from Grave No.179, Yanghai No.2 cemetery as an example. The boots are made from raw animal leather with the sole, vamp and bootleg as a separated piece respectively. The vamp and upper-in-one is stitched to the sole and then the bootleg is stitched to the former whole. This kind of vamp and upperin-one structure has higher requirements for accuracy, boasting more suitable shape and structure. It effectively reduces parting line on the vamp and enhances comfort level, thus becoming commencement of modern footwear structure. In addition, due to the lack of necessity to stitch the bootleg to the sole, the bootleg is rather changeful. For example, prehistoric Subeixi male wears panty leather boots and female wears leather felt boots. Felt or soft sheepskin is stitched to the bootleg or sheepskin is decorated on the knee part of bootleg, forming unique regional features. "Fig. 7" 


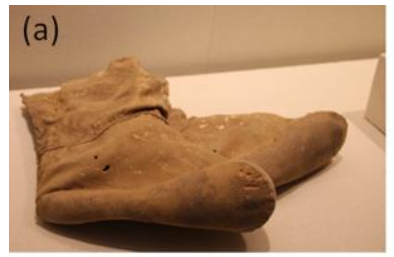

(b)

(c)

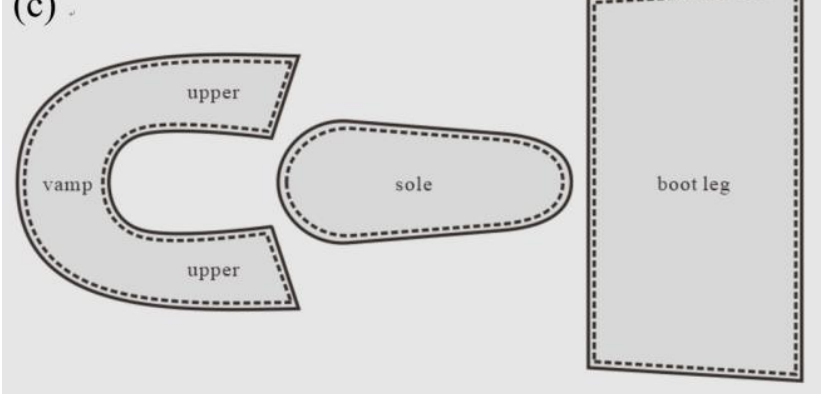

(a) Photo (b) Sketch (c) Pattern of the structure

Fig. 7. Upper \&vamp-in-one leather boots with three-pieces structure unearthed from Yanghai cemetery.

\section{2) Pleated-sewing panty leather boots}

Apart from short boots, thigh-high boots get popular in this period. The nation on horseback wearing pants as major bottoms wears thigh-high boots outside the woolen pants for protection against cold and agile appearance convenient for riding and shooting. Shape and structure of thigh-high boots fall into two types: thigh-high boots and panty boots. Structure of thigh-high boots is similar to that of ankle boots, and the only difference lies in length. Panty boots get popular in Turpan Basin of later phase and are mainly unearthed from Yanghai and Subeixi cemetery, Shanshan. They are the combination of boots and pants. The bootleg above the knee and the vamp blend into one harmonious whole, which is pleated and directly stitched to the sole. Holes are made at the upper edge of bootleg, and cords go through the holes and are tied at people's waist in wearing, boasting extremely unique shape and structure.

Take the panty boots worn by the male unearthed from Subeixi M10 as an example. They are about $105 \mathrm{~cm}$ long and $32 \mathrm{~cm}$ wide, made from sheepskin. The bootleg is as high as thigh root in horn form as a whole with bootleg and vamp-in-one. The sole is a separated piece. Due to the large piece of leather material of vamp, the combined bootleg gets pleated and stitched to the sole using the turned-stitching techniques[12]. The whole boot becomes gradually wide from bottom to top for the convenience of lower limbs' movement. In addition, a piece of triangle sheepskin is stitched to the upper edge of bootleg with pinholes through which the cord goes for fixation at the waist as kneecap, playing a dual role of structure and function. The panty boots with bootleg and sole-stitched-in-one have excellent thermal insulation properties, suitable for the dry and cold weather in Xinjiang. "Fig. 8"
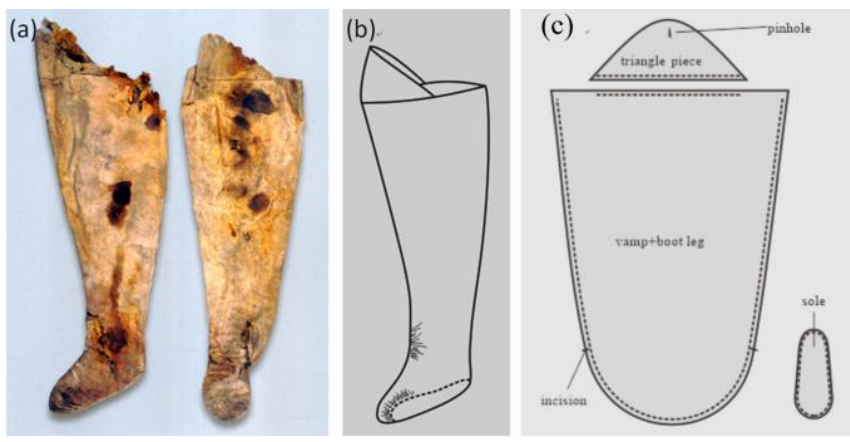

(a) Photo (b) Sketch (c) Pattern of the structure

Fig. 8. Pleated-sewing leather boots unearthed from Subeixi cemetery.

\section{B. Sewing Craft}

With further improvement of leather tanning, ancient residents in this period have better access to tanning craft and footwear manufacturing techniques. Seen from footwear with pleated-sewing sole or vamp, we can know that footwear at this time has fine and smooth surface with more reasonable structure. In terms of stitching techniques of boot sole, based on the original direct-stitching and turnedstitching, pleated stitching appears. In terms of selection of leather material, multiple types of leather material appear, like wild goat skin and deerskin, reflecting further improvement of ancient residents' leather processing technique in Xinjiang in this period.

\section{CONCLUSION}

Prehistoric footwear unearthed from Xinjiang is mainly made from animal skin and fur and felt in the shape of leather boots, structure tending to be reasonable in the almost 2000 years' constant development and change. Leather boots of early phase have achieved separated upper and sole, three separated pieces of sole, vamp and bootleg, two separated pieces of vamp and bootleg-in-one and the sole, both "direct-stitching" and "turned-stitching" techniques in terms of sole and vamp sewing craft and mature structure and craft features. In the mid-term phase, the leather boots get improved with appearance of special shape and structure, like flat pointed boots and folded warped boots. With domestication of horse and formation of nomadic life style, pants begin to appear in ancient residents' life in Xinjiang, accompanying the shortening of tops, length increase of bootleg and appearance of the fourpiece boots structure of sole, vamp, upper and bootleg. In the later phase, shape and structure of leather boots had been further developed with the three-piece structure with vamp and upper-in-one, making it possible to stitch bootleg to the joint vamp. Bootleg material also becomes abundant. In addition, In Subeixi culture of Turpan Basin, various types of footwear, like thigh-high boots and panty boots, are matched with short tops, reflecting male residents of Turpan Basin in this period have begun the life of riding and shooting. However, female still mainly wears redingote and long dresses, reflecting the evident social division of labor. Pleated-sewing craft begins to appear in footwear manufacturing, reflecting progress of tanning craft in this 
period. Leather material becomes abundant, fine and smooth, making it easy for modeling. Shape and structure of footwear also become diversified. In a word, structure and craft of prehistoric leather boots unearthed from Xinjiang constantly develop in the almost 2000 years, reflecting ancient residents' primitive wisdom and aesthetic psychology in Xinjiang and pulling open the prelude of evolution of Chinese footwear's shape and structure.

\section{REFERENCES}

[1] Guo Wu. Archaeological Research on Prehistoric Society of Later Period of Xinjiang[M]. Shanghai: Shanghai Chinese Classics Publishing House, 2012:19.

[2] Zhang Qiuping, Yuan Xiaoli. Collected Works of China Design(Volume 6/Costume/Hats and Shoes) [M].Beijing: Commercial Press, Shenzhen: Haitian Press, 2012: 106.

[3] Shi You(Han). Fast Learning[M].Changsha: Yuelu Publishing House, 1989: 12.

[4] Liu Xi(Han). Notes to Nominations[M].Beijing: Zhonghua Book Company, 1985: 83.

[5] Xinjiang Aeological Research Institution. Xinjiang Lop Nor Xiaohe Cemetery 2003 Excavation Bulletin[J].Cultural Relics. 2007(10): 21-22.

[6] Bergman, translated by Wang An'hong. Xinjiang Archaeological Record[M].Urumchi: Volksverlag Xinjiang, 1997: 184-185.

[7] Vivi Sylwan, Woollen Textiles of the Loulan People [M]. Siockholm: Tryckeri Aktiebolaget Thule,1941: 44.

[8] Luo Chongqi. Historical Narrative of China Leather[J].Leather Technology, 1989(2): 17-18.

[9] Xinjiang Turpan Research Institute, Xinjiang Aeological Research Institution. Xinjiang Yanghai Cemetery of Shanshan Excavation Bulletin[J].Chinese Journal of Archaeology, 2011(1): 120.

[10] Hami Museum, Hami Cultural Relics Essence[M]. Beijing: Science Press, 2013: 119.

[11] Xinjiang Aeological Research Institution. Grave 151 and 152, Wubao Cemetery, Hami, Xinjiang[J].Xinjiang Cultural Relics, 1992(3): 8

[12] Xinjiang Uygur Autonomous Region Museum. Costume Collection of Ancient Western Regions[M].Beijing: Cultural Relics Publishing House, 2010: 38. 